\title{
Produksi dan Kandungan Mineral Pueraria phaseoloides dengan Tingkat Naungan dan Inokulasi Mikoriza Berbeda
}

\author{
Production and Mineral Content of Pueraria phaseoloides in Various Shading Levels and \\ Micorrhiza Inoculation
}

\author{
A. I. M. Alia ${ }^{\#}$, Yakup $^{\mathrm{b} \#, ~ \& ~ S a b a r u d d i n}{ }^{\text {\# }}$ \\ a'Bagian Tanaman Pakan dan Manajemen Pastura, Jurusan Peternakan, Fakultas Pertanian, Universitas Sriwijaya \\ ${ }^{\mathrm{b} B a g i a n}$ Ekologi Tanaman, Jurusan Budidaya Pertanian, Fakultas Pertanian, Universitas Sriwijaya \\ 'Bagian Biologi Tanah, Jurusan Ilmu Tanah, Fakultas Pertanian, Universitas Sriwijaya \\ \#Jln. Palembang- Indralaya Km. 32 Ogan Ilir, Sumatera Selatan
}

(Diterima 06-05-2010; disetujui 10-10-2010)

\begin{abstract}
Problems of forage management in the integration of livestock into oil palm and rubber plantations in Indonesia are declining of light as the canopy of the plant increases and acid soils containing low available $\mathrm{P}, \mathrm{Cu}$, and $\mathrm{Zn}$. The objective of experiment was to study the effect of shading and arbuscular mycorrhizal fungi (AMF) inoculations on the production and content of $P, C u$, and $\mathrm{Zn}$ of Pueraria phaseoloides (Roxb.) Benth (puero). The experiment was arranged according to the split plot design with three replicates in a green house. Treatments tested were shading as the main plot $(0 \%, 25 \%, 50 \%$, and $75 \%)$ and AMF inoculations as sub plots (indigenous AMF, Glomus manihotis, indigenous AMF + G. manihotis and no inoculation). Root biomass was affected by shading level while leaf stem ratio was affected by both shading level and AMF inoculations. Inoculations with $G$. manihotis and indigenous $+G$. manihotis indicated higher herbage production and $P$ contents than inoculations with indigenous AMF. Effectiveness of AMF inoculation on improvement of production and $P$ uptake varied according to shading conditions. $P$. phaseoloides was tolerant to shading up to $50 \%$ and its production and $P$ content as responses on inoculation of AMF were affected by soil conditions and shading intensity. Inoculation of G. manihotis and its combination with indigenous AMF improved production and $P$ content of Pueraria phaseoloides in shading level upto $50 \%$.
\end{abstract}

Key words: herbage production, arbuscular mycorrhizal, Pueraria phaseoloides, shading

\section{PENDAHULUAN}

Sistem integrasi ternak dengan perkebunan merupakan salah satu alternatif upaya pengembangan agribisnis peternakan dan perkebunan (Latif \& Mamat, 2002). Permasalahan utama dalam manajemen tanaman pakan di dalam sistem ini, diantaranya adalah produksi tanaman pakan yang menurun seiring dengan bertambahnya tingkat naungan karena meningkatnya umur tanaman pokok perkebunan. Selain itu, sebagian besar tanah perkebunan bersifat masam dengan ketersediaan $\mathrm{N}$, P, dan $\mathrm{K}$ yang rendah, tetapi $\mathrm{Al}$, Fe dan $\mathrm{Mn}$ tinggi, sehingga menurunkan produksi tanaman dan mempengaruhi asupan mineral pada ternak.

\footnotetext{
* Korespondensi:

Bagian Tanaman Pakan dan Manajemen Pastura, Jurusan Peternakan,

Fakultas Pertanian Universitas Sriwijaya

Jln. Palembang- Indralaya Km. 32 Ogan Ilir, Sumatera Selatan

E-mail: indranutrisi@yahoo.co.id.
}

Pertumbuhan kanopi tanaman pokok yang mengurangi penetrasi cahaya ke permukaan tanah menyebabkan penurunan produksi hijauan pakan di perkebunan kelapa sawit (Ezenwa et al., 1996) maupun tanaman perkebunan lainnya (Das et al., 2008; Kurniawan et al., 2007). Keterbatasan cahaya, di sisi lain mendorong adanya aklimatisasi morfologis tanaman pakan untuk mengkompensasi rendahnya laju fotosintesis per unit luasan daun melalui peningkatan rasio tajuk:akar, batang:daun, serta rasio berat luasan daun (Wong et al., 2005).

Sebagian tanah di area perkebunan kelapa sawit dan karet adalah tanah masam dan defisien beberapa mineral tanah. Evitariani et al. (2006) menunjukkan bahwa defisiensi P dan S terjadi pada 50\% legum hijauan pakan. Warly et al. (2006a) melaporkan bahwa defisiensi P terjadi pada 78,6\% legum hijauan pakan, Mg (14,3\%) dan S (28,6\%). Warly et al. (2006b) menunjukkan bahwa sebagian besar legum mengalami defisiensi $\mathrm{Cu}(78,6 \%)$, Zn (57,1\%), Mn (21,4\%), Mo (42,9\%) and Co (50\%) sedangkan Mn hanya defisien pada Gliricidia maculata. 
Fungi mikoriza arbuskular (FMA) telah terbukti meningkatkan pertumbuhan tanaman pada kondisi tanah yang masam (Kanno et al., 2006), maupun pada kondisi intensitas cahaya matahari yang rendah (Shukla et al., 2009). Chen \& Zhao (2009) menunjukkan bahwa FMA dapat memperbaiki serapan unsur $\mathrm{K}, \mathrm{Ca}, \mathrm{Mg}$, $\mathrm{Cu}$, $\mathrm{Zn}, \mathrm{Fe}$ dan Mn tanaman Astragalus sinicus L pada tanah dengan penambahan logam berat Lantanum. Cumming \& Ning (2003) menunjukkan bahwa simbiosis FMA dapat meningkatkan serapan $\mathrm{P}, \mathrm{Cu}$, dan $\mathrm{Zn}$ serta resistensi tanaman terhadap toksisitas Al. Keberadaan FMA juga dapat mereduksi akumulasi Fe dan Mn pada tanah masam.

Pueraria phaseoloides (Roxb.) Benth (puero) toleran pada intensitas cahaya rendah dan tinggi dengan produktivitas 10 ton bahan kering per ha serta palatabilitas yang baik (Valentim \& Andrade, 2005). Hijauan pakan ini dapat bersimbiosis dengan Glomus manihotis (Sieverding, 1991; Musandu \& Giller, 1994), maupun dengan jenis FMA yang lain (Kramadibrata \& Gunawan, 2006; Lukiwati, 2007). Beberapa FMA diharapkan mampu meningkatkan produksi legum khususnya puero pada kondisi tingkat penyinaran rendah. Oleh karena itu perlu dilakukan kajian pengaruh tingkat naungan serta inokulasi beberapa FMA terhadap produksi hijauan serta kandungan $\mathrm{P}, \mathrm{Cu}$, dan $\mathrm{Zn}$ legum puero.

\section{MATERI DAN METODE}

\section{Kondisi Penelitian}

Penelitian ini dilaksanakan di Fakultas Pertanian Universitas Sriwijaya, Indralaya, Sumatera Selatan dari bulan Agustus 2008 sampai dengan April 2009 dengan kondisi curah hujan bulanan berkisar 14-390 mm dengan jumlah hari hujan berkisar 2-13 hari. Suhu udara rata-rata bulanan berkisar $26,3-27,5{ }^{\circ} \mathrm{C}$ sedangkan kelembaban nisbi udara berkisar 78\%-90\% (Stasiun Klimatologi Kenten, 2010).

\section{Materi}

Media tanam dan inokulum indigenous diambil dari area perkebunan karet berumur 1 tahun yang ditutupi oleh gulma Axonopus compressus, Imperata cylindrica, Mimosa pudica, Paspalum conjugatum, Ottochloa nodosa, Mikania cordata, dan Asystasia gangetica. Tanah untuk media tanam dihaluskan dan dipasteurisasi 2 kali secara bertahap masing-masing sekitar 60 menit pada suhu $100{ }^{\circ} \mathrm{C}$ dengan autoklaf. Suhu tersebut dipertahankan selama 2 jam dan selanjutnya dibiarkan sampai dingin. Tanah disimpan selama satu minggu pada suhu ruang untuk mengecambahkan spora FMA yang tersisa sebelum dilakukan pasteurisasi kedua (modifikasi metode Sieverding, 1991). Tanah yang sudah dipasteurisasi (Tabel 1) dimasukkan ke dalam polibag (10 kg/polibag).

\section{Metode}

Pengaturan naungan. Perlakuan naungan $(0 \%, 25 \%$, $50 \%$, dan $75 \%$ ) disusun dengan membangun rumah bayang yang ditutupi dengan plastik pada rangka kayu. Luas rumah bayang yang dibangun adalah $8 \mathrm{~m}^{2}$ dengan tinggi 1,80 m. Paranet dibentangkan sedemikian rupa sehingga menutupi seluruh bangunan. Rumah bayang tidak ditutup paranet pada perlakuan $0 \%$ naungan. Hasil pengukuran tingkat naungan dengan lux meter digital (TES Electrical Electronics Corporation, Taiwan) menunjukkan rataan angka 31, 49, 71, dan 86 klx.

Inokulasi dan penanaman. Benih legum puero diskarifikasi dengan merendamnya dalam air panas (100 $\left.{ }^{\circ} \mathrm{C}\right)$ selama 10 detik dan selanjutnya dibilas dengan air dingin $\left(26^{\circ} \mathrm{C}\right)$. Setelah berkecambah, 8 benih diletakkan dalam polibag bersamaan dengan inokulasi FMA (10 $\mathrm{g}$ /benih) sesuai perlakuan yang diberikan. Inokulum yang digunakan adalah $G$. manihotis (22,50 spora/g) dengan media pasir kali dan inokulum FMA indigenous. Inokulum FMA indigenous merupakan inokulum tanah, yang mengandung akar terkoloni, hifa dan spora FMA. Rataan kepadatan spora dalam inokulum FMA indigenous adalah 34,33 spora/g yang berjenis Glomus, Entrophospora, Gigaspora.

Setelah 1 minggu dipilih 4 tanaman terbaik dengan pertumbuhan yang seragam (Sieverding, 1991). Inokulasi dilakukan dengan menaburkan inokulum di samping benih dan selanjutnya ditutup dengan tanah pasteurisasi. Standar pemupukan yang diterapkan adalah 0,54 g per polibag (50 kg urea/ha) dan 0,84 g/polibag KCl (100 $\mathrm{kg} \mathrm{K}$ O/ha) (Lukiwati, 2007). Penyiraman dilakukan 2 kali dalam seminggu (500 ml air setiap kali penyiraman) sampai dengan pemotongan hijauan. Suhu tanah diukur 3 kali seminggu pada kedalaman $5 \mathrm{~cm}$ pada

Tabel 1. Karakteristik tanah yang telah dipasteurisasi sebagai media pertumbuhan

\begin{tabular}{lrc}
\hline Parameter & Nilai & Keterangan* \\
\hline $\mathrm{pH} \mathrm{H} \mathrm{H}_{2}(1: 1)$ & 4,72 & Masam \\
$\mathrm{pH} \mathrm{KCl} \mathrm{(1:1)}$ & 3,83 & \\
C-Organik (\%) & 3,18 & Tinggi \\
N-Total (\%) & 0,25 & Sedang \\
$\mathrm{CN}$ & 13,00 & Sedang \\
$\mathrm{P}-\mathrm{Bray}(\mathrm{mg} / \mathrm{kg})$ & 22,90 & Sangat tinggi \\
$\mathrm{K} \mathrm{dd}\left(\mathrm{Cmol}^{+} / \mathrm{kg}\right)$ & 0,26 & Rendah \\
$\mathrm{Na}\left(\mathrm{Cmol}^{+} / \mathrm{kg}\right)$ & 0,33 & Rendah \\
$\mathrm{Ca}\left(\mathrm{Cmol}^{+} / \mathrm{kg}\right)$ & 1,85 & Sangat rendah \\
$\mathrm{Mg}\left(\mathrm{Cmol}^{+} / \mathrm{kg}\right)$ & 0,35 & Sangat rendah \\
$\mathrm{KTK}\left(\mathrm{Cmol}^{+} / \mathrm{kg}\right)$ & 9,79 & Rendah \\
$\mathrm{Al} \mathrm{dd}\left(\mathrm{Cmol}^{+} \mathrm{kg}\right)$ & 0,12 & \\
$\mathrm{H} \mathrm{dd}\left(\mathrm{Cmol}^{+} / \mathrm{kg}\right)$ & 0,16 & \\
Tekstur: $\mathrm{Pasir}(\%)$ & 69,54 & \\
Debu (\%) $_{2}$ & 18,88 & \\
\hline
\end{tabular}

Keterangan: $\mathrm{dd}=$ dapat ditukar; $\mathrm{Cmol}^{+}=\mathrm{cation} \mathrm{mol} / \mathrm{kg}$. Sumber: Laboratorium Tanah Fakultas Pertanian Universitas Sriwijaya. 
pukul 14.00-15.00 WIB, sedangkan intensitas cahaya diukur 3 kali pada bulan September dan Oktober.

Pemotongan dan analisis hijauan pakan. Pemotongan tanaman pakan dilakukan setelah 60 hari penanaman. Tanaman dipotong pada permukaan tanah untuk menentukan produksi bahan kering hijauan tiap polibag dan selanjutnya dipisahkan antara batang dan daun untuk mendapatkan rasio batang:daun. Setelah pemisahan, dilakukan pengeringan pada $105{ }^{\circ} \mathrm{C}$ selama 12 jam (Balai Penelitian dan Pengembangan Pertanian, 2005). Penimbangan akar dilakukan 2 minggu setelah pemotongan hijauan dan selanjutnya dikeringkan selama 12 jam pada suhu $105{ }^{\circ} \mathrm{C}$, untuk menentukan produksi bahan kering akar serta rasio tajuk:akar.

Rancangan percobaan dan analisis data. Percobaan menggunakan rancangan petak terbagi dengan 3 ulangan. Perlakuan terdiri atas 4 tingkat naungan $(0 \%, 25 \%, 50 \%$, dan $75 \%)$ sebagai petak utama dan 4 macam inokulasi FMA, yaitu: indigenous, G. manihotis, indigenous + G. manihotis dan tanpa inokulasi sebagai anak petak. Analisis ragam dilakukan untuk menganalisa pengaruh perlakuan. Perbedaan yang nyata antara rataan hasil perlakuan selanjutnya diuji dengan beda nyata terkecil. Pengukuran efektivitas inokulasi FMA terhadap produksi dan penyerapan P dilakukan dengan menghitung produktivitas dan konsentrasi $\mathrm{P}$ hijauan puero dengan inokulasi dan tanpa inokulasi FMA (Bolan, 2001).

Efektivitas FMA terhadap produksi bahan kering= $\underline{\text { Produksi bahan kering hijauan dengan FMA }} \times 100 \%$ Produksi bahan kering hijauan tanpa FMA

Efektivitas FMA terhadap penyerapan $\mathrm{P}=$ Kandungan P hijauan dengan FMA $\times 100 \%$ Kandungan $P$ hijauan tanpa FMA

\section{HASIL DAN PEMBAHASAN}

\section{Produksi Bahan Kering Hijauan}

Naungan, inokulasi FMA dan interaksinya berpengaruh $(\mathrm{P}<0,01)$ terhadap produksi bahan kering hijauan puero. Peningkatan produksi hijauan puero seiring dengan peningkatan naungan dari 0 sampai 50\%. Produksi bahan kering hijauan tertinggi diperoleh pada 50\% tingkat naungan dibandingkan pada tingkat naungan lainnya (Tabel 2). Puero beradaptasi lebih baik terhadap naungan dibandingkan dengan yang dilaporkan Wong et al. (2005) yang menunjukkan bahwa puero merupakan legum yang tahan pada pencahayaan yang rendah $(30 \%)$.

Peningkatan produksi bahan kering hijauan puero seiring dengan peningkatan tingkat naungan dari $0 \%$ sampai dengan 50\% ini berkaitan erat dengan kemampuan adaptasi puero pada pencahayaan rendah, juga berkaitan dengan suhu tanah yang dipengaruhi oleh tingkat naungan $(\mathrm{P} \varangle 0,01)$. Suhu tanah pada naungan $0 \%$, $25 \%$, 50\%, dan $75 \%$ adalah berturut-turut 32,58; 30,43; 29,59; dan $27,74{ }^{\circ} \mathrm{C}$. Sieverding (1991) mengemukakan bahwa suhu tanah yang berkisar $25-30{ }^{\circ} \mathrm{C}$ merupakan suhu optimum untuk perkembangan dan efektivitas FMA. Suhu tanah di bawah naungan lebih rendah dibanding tanpa naungan, sehingga ketersediaan nitrogen tanah, mineral, kandungan air dan aktivitas mikroba lebih tinggi (Schroth et al., 2001). Kondisi tersebut mendukung pertumbuhan dan perkembangan asosiasi simbiosis puero dengan FMA.

Produksi bahan kering hijauan lebih tinggi $(\mathrm{P} \varangle 0,05)$ dengan inokulasi FMA dibanding tanpa inokulasi. Peningkatan kandungan $\mathrm{P}$ akibat inokulasi ternyata mampu meningkatkan pertumbuhan tanaman yang ditunjukkan oleh peningkatan produksi bahan kering hijauan. Produksi bahan kering hijauan pada perlakuan inokulasi FMA lebih tinggi $(\mathrm{P} \varangle 0,05)$ dibanding tanpa inokulasi pada $0 \%, 25 \%$, dan $50 \%$ tingkat naungan tetapi berbeda tidak nyata pada $75 \%$ tingkat naungan. Keterbatasan cahaya sebagai sumber energi untuk fotosintesis yang ditangkap klorofil pada $75 \%$ tingkat naungan mengakibatkan terhambatnya fungsi FMA dalam meningkatkan produksi tanaman.

Efektivitas FMA terhadap produksi bahan kering dipengaruhi oleh jenis FMA yang diinokulasikan $(\mathrm{P} \varangle$ 0,01). Efektivitas produksi bahan kering dengan inokulasi G. manihotis tidak berbeda nyata dengan inokulasi indigenous + G. manihotis tetapi lebih tinggi $(\mathrm{P} \varangle 0,05)$ dibanding perlakuan FMA indigenous (Tabel 3). Inokulasi G. manihotis memiliki pengaruh yang lebih baik terhadap produksi bahan kering dibandingkan FMA indigenous. Hal ini berkaitan dengan kesesuaian dan efektivitas asosiasi simbiosis G. manihotis dengan tanaman puero (Sieverding, 1991).

Tabel 2. Produksi bahan kering hijauan (g) pada beberapa tingkat naungan dan inokulasi fungi mikoriza arbuskular (FMA)

\begin{tabular}{lcccc}
\hline \multirow{2}{*}{ FMA } & \multicolumn{5}{c}{ Tingkat naungan } \\
\cline { 2 - 5 } & $0 \%$ & $25 \%$ & $50 \%$ & $75 \%$ \\
\hline Indigen & $8,57 \pm 2,01^{\mathrm{b}}$ & $9,10 \pm 0,56^{\mathrm{ab}}$ & $14,08 \pm 1,70^{\mathrm{b}}$ & $1,06 \pm 0,41^{\mathrm{a}}$ \\
G. manihotis & $11,06 \pm 1,61^{\mathrm{b}}$ & $12,08 \pm 1,99^{\mathrm{c}}$ & $14,03 \pm 2,01^{\mathrm{b}}$ & $1,85 \pm 0,45^{\mathrm{a}}$ \\
Indigen + G. manihotis & $10,15 \pm 0,34^{\mathrm{b}}$ & $10,94 \pm 1,09^{\mathrm{bc}}$ & $15,66 \pm 1,93^{\mathrm{b}}$ & $1,17 \pm 0,21^{\mathrm{a}}$ \\
Tanpa inokulasi & $5,57 \pm 0,35^{\mathrm{a}}$ & $7,43 \pm 2,89^{\mathrm{a}}$ & $7,42 \pm 3,34^{\mathrm{a}}$ & $0,82 \pm 0,14^{\mathrm{a}}$ \\
\hline
\end{tabular}

Keterangan: Superskrip berbeda pada kolom yang sama menunjukkan berbeda nyata (P $\varangle, 05)$. 
Tabel 3. Efektivitas fungi mikoriza arbuskular (FMA) terhadap produksi bahan kering (\%)

\begin{tabular}{lccccc}
\hline \multirow{2}{*}{ FMA } & \multicolumn{5}{c}{ Tingkat naungan } \\
\cline { 2 - 5 } & $0 \%$ & $25 \%$ & $50 \%$ & $75 \%$ & \multirow{2}{*}{ Rataan } \\
\hline Indigen & $153,48 \pm 30,36$ & $131,89 \pm 36,86$ & $221,62 \pm 106,22$ & $132,66 \pm 57,29$ & $159,91 \pm 67,30^{\mathrm{a}}$ \\
G. manihotis & $197,90 \pm 17,09$ & $170,99 \pm 32,98$ & $226,70 \pm 131,27$ & $223,46 \pm 19,84$ & $204,76 \pm 63,29^{\mathrm{b}}$ \\
Indigen + G. manihotis & $182,61 \pm 10,79$ & $157,10 \pm 38,42$ & $251,57 \pm 141,17$ & $147,71 \pm 50,65$ & $184,75 \pm 78,62^{\mathrm{b}}$ \\
Rataan & $178,00 \pm 26,73$ & $153,33 \pm 35,71$ & $233,29 \pm 110,92$ & $167,94 \pm 57,76$ & \\
\hline
\end{tabular}

Keterangan: superskrip berbeda pada kolom yang sama menunjukkan berbeda nyata $(\mathrm{P} \varangle 0,05)$.

\section{Kandungan $\mathrm{P}, \mathrm{Cu}$, dan $\mathrm{Zn}$}

Naungan, inokulasi FMA dan interaksi keduanya berpengaruh $(\mathrm{P}<0,01)$ terhadap kandungan $\mathrm{P}$ hijauan puero. Kandungan $\mathrm{P}$ pada naungan $50 \%$ lebih tinggi $(\mathrm{P} \varangle 0,05)$ dibanding kandungan $\mathrm{P}$ pada tingkat naungan lainnya. Korhonen et al. (2004) mengemukakan bahwa produktivitas Geranium sylvaticum lebih tinggi pada intensitas cahaya rendah $(2-12 \mathrm{klx})$ dibanding pada intensitas cahaya tinggi (95-106 klx). Shukla et al. (2009) melaporkan bahwa peningkatan bahan kering dan kandungan $\mathrm{P}$ terjadi seiring dengan penurunan naungan pada Phaseolus mungo dan Triticum aestivum.

Kandungan $\mathrm{P}$ pada perlakuan G. manihotis tidak berbeda nyata dengan pengaruh perlakuan indigenous + G. manihotis tetapi lebih tinggi $(\mathrm{P} \varangle 0,05)$ daripada perlakuan tanpa inokulasi dan indigenous. Lebih tingginya kandungan P pada tanaman dengan FMA menunjukkan bahwa FMA dapat meningkatkan kandungan $P$ hijauan puero (Tabel 4). Kandungan $\mathrm{P}$ pada perlakuan dengan FMA lebih tinggi $(\mathrm{P} \varangle 0,05)$ dibandingkan perlakuan tanpa inokulasi pada $0 \%, 25 \%$ dan $50 \%$ tingkat naungan tetapi berbeda tidak nyata pada $75 \%$ tingkat naungan. Hal tersebut menunjukkan bahwa pada $75 \%$ tingkat naungan, FMA tidak berfungsi dalam meningkatkan serapan $P$ pada tanaman puero.

Efektivitas pengaruh FMA terhadap penyerapan $P$ dipengaruhi $(\mathrm{P} \varangle 0,05)$ oleh perlakuan naungan. Rataan efektivitas FMA dalam penyerapan $\mathrm{P}$ di atas $100 \%$ pada tingkat naungan $0 \%$, 25\%, dan $50 \%$ tetapi di bawah $100 \%$ pada $75 \%$ tingkat naungan. Hal ini berarti bahwa pada tingkat naungan $0 \%, 25 \%$, dan $50 \%$ masih terlihat adanya peran FMA dalam penyerapan $\mathrm{P}$ tetapi hal ini tidak terjadi pada $75 \%$ tingkat naungan.

Tabel 4. Kandungan $\mathrm{P}(\mathrm{g} / \mathrm{kg} \mathrm{BK}), \mathrm{Cu}$ dan $\mathrm{Zn}(\mathrm{mg} / \mathrm{kg} \mathrm{BK})$ hijauan pada beberapa tingkat naungan dan inokulasi fungi mikoriza arbuskular (FMA)

\begin{tabular}{|c|c|c|c|c|c|}
\hline \multirow{2}{*}{ FMA } & \multicolumn{4}{|c|}{ Tingkat naungan } & \multirow{2}{*}{ Rataan } \\
\hline & $0 \%$ & $25 \%$ & $50 \%$ & $75 \%$ & \\
\hline \multicolumn{6}{|l|}{ Kandungan $\mathrm{P}$} \\
\hline Indigen & $0,09 \pm 0,05^{\mathrm{b}}$ & $0,08 \pm 0,01^{\mathrm{ab}}$ & $0,13 \pm 0,01^{\mathrm{b}}$ & $0,04 \pm 0,01^{\mathrm{a}}$ & \\
\hline G. manihotis & $0,10 \pm 0,03^{\mathrm{b}}$ & $0,12 \pm 0,01^{\mathrm{c}}$ & $0,13 \pm 0,01^{\mathrm{b}}$ & $0,03 \pm 0,00^{\mathrm{a}}$ & \\
\hline Indigen $+G$. manihotis & $0,10 \pm 0,03^{b}$ & $0,10 \pm 0,00^{\mathrm{b}}$ & $0,13 \pm 0,01^{b}$ & $0,03 \pm 0,00^{\mathrm{a}}$ & \\
\hline Tanpa inokulasi & $0,05 \pm 0,01^{\mathrm{a}}$ & $0,07 \pm 0,01^{\mathrm{a}}$ & $0,10 \pm 0,01^{\mathrm{a}}$ & $0,04 \pm 0,01^{a}$ & \\
\hline \multicolumn{6}{|l|}{ Kandungan $\mathrm{Cu}$} \\
\hline Indigen & $0,76 \pm 0,06$ & $0,85 \pm 0,18$ & $0,86 \pm 0,17$ & $0,74 \pm 0,05$ & $0,80 \pm 0,12$ \\
\hline G. manihotis & $0,78 \pm 0,14$ & $0,77 \pm 0,19$ & $0,70 \pm 0,02$ & $0,70 \pm 0,08$ & $0,73 \pm 0,11$ \\
\hline Indigen $+G$. manihotis & $0,88 \pm 0,19$ & $0,99 \pm 0,31$ & $0,76 \pm 0,15$ & $0,66 \pm 0,08$ & $0,82 \pm 0,22$ \\
\hline Tanpa inokulasi & $0,73 \pm 0,24$ & $0,76 \pm 0,08$ & $0,75 \pm 0,01$ & $0,65 \pm 0,18$ & $0,72 \pm 0,14$ \\
\hline Rataan & $0,79 \pm 0,16$ & $0,84 \pm 0,20$ & $0,77 \pm 0,12$ & $0,69 \pm 0,10$ & \\
\hline \multicolumn{6}{|l|}{ Kandungan Zn } \\
\hline Indigen & $4,22 \pm 0,30$ & $3,91 \pm 0,29$ & $4,30 \pm 1,11$ & $4,18 \pm 0,22$ & $4,15 \pm 0,53$ \\
\hline G. manihotis & $4,55 \pm 0,46$ & $4,41 \pm 0,18$ & $3,69 \pm 0,13$ & $4,59 \pm 1,38$ & $4,31 \pm 0,74$ \\
\hline Indigen $+G$. manihotis & $4,39 \pm 0,10$ & $4,27 \pm 0,31$ & $4,11 \pm 0,25$ & $3,89 \pm 0,21$ & $4,17 \pm 0,28$ \\
\hline Tanpa inokulasi & $4,13 \pm 0,31$ & $3,70 \pm 0,30$ & $3,56 \pm 0,04$ & $4,20 \pm 0,29$ & $3,90 \pm 0,36$ \\
\hline Rataan & $4,32 \pm 0,32$ & $4,07 \pm 0,38$ & $3,92 \pm 0,58$ & $4,22 \pm 0,67$ & \\
\hline
\end{tabular}

Keterangan: Superskrip berbeda pada kolom yang sama menunjukkan berbeda nyata $(\mathrm{P} \varangle, 05)$. 
Keberadaan FMA pada akar tanaman puero pada 75\% tingkat naungan cenderung mengakibatkan penurunan kandungan $\mathrm{P}$ tanaman (Tabel 5).

Inokulasi FMA meningkatkan kandungan $P$ (Ricardo et al., 2000; Shukla et al., 2009; Cumming \& Ning, 2003) serta bersinergis dengan keberadaan rhizobium penambat nitrogen (Nusantara, 2002). Kisaran kandungan $\mathrm{P}$ puero penelitian ini berbeda dengan yang dikemukakan oleh Rueda et al. (2003), yaitu $8 \mathrm{~g} / \mathrm{kg}$, tetapi sama dengan Shukla et al. (2009) pada tanaman Phaseolus mungo dan Triticum aestivum dengan media tanam yang disterilisasi. Inokulasi FMA dapat meningkatkan kandungan $\mathrm{P}$, tetapi kandungan $\mathrm{P}$ puero tersebut tidak mencukupi kebutuhan ternak ruminansia pada daerahdaerah tropis. Tingkat kritis kebutuhan $\mathrm{P}$ berdasarkan Ruminant National and Agricultural Research Councils, yaitu sebesar 2,5 g/kg bahan kering (McDowell, 1997). Namun demikian, inokulasi FMA berperan dalam mengurangi tingkat defisiensi P pada pakan ternak.

Interaksi naungan dan FMA mempengaruhi $(\mathrm{P} \varangle 0,01)$ produksi bahan kering hijauan dan kandungan P. Produksi bahan kering hijauan dan kandungan $\mathrm{P}$ tertinggi diperoleh pada $50 \%$ naungan dengan inokulasi FMA walaupun efektivitas penyerapan $\mathrm{P}$ tertinggi tidak pada 50\% naungan. Hal ini menunjukkan bahwa produksi hijauan tidak hanya dipengaruhi oleh efektivitas FMA terhadap penyerapan P saja (Shukla et al., 2009; Schroth et al., 2001). Tidak adanya perbedaan antara G. manihotis dengan kombinasi antara indigenous $+G$. manihotis mengindikasikan bahwa terjadi kesesuaian antara kedua jenis FMA dalam menunjang produksi hijauan puero pada tingkat naungan $0 \%, 25 \%$, dan $50 \%$. Hal ini berarti bahwa indigenous $+G$. manihotis pada hijauan puero di perkebunan dengan keterbatasan cahaya akan lebih meningkatkan produksi hijauan dan kan- dungan $\mathrm{P}$ dibandingkan jika hanya FMA indigenous saja.

\section{Produksi Akar dan Rasio Tajuk:Akar}

Produksi bahan kering akar menurun seiring dengan peningkatan tingkat naungan (Tabel 6). Du et al. (2009) melaporkan bahwa adanya penurunan berat akar seiring dengan penurunan intensitas cahaya pada Trifolium repens. Hal ini menunjukkan adanya perubahan morfologis tanaman puero untuk menyesuaikan diri dengan semakin menurunnya cahaya yang berkaitan dengan laju fotosintesis tanaman. Perlakuan FMA tidak mempengaruhi produksi bahan kering akar. Du et al. (2009) menunjukkan adanya penurunan berat akar dengan inokulasi FMA. Li et al. (2009) melaporkan bahwa Vigna radiata $L$. tidak menunjukkan perbedaan dalam biomasa akarnya antara tanaman yang bermikoriza dengan tanaman tanpa mikoriza.

Rasio tajuk:akar peuro dipengaruhi $(\mathrm{P} \varangle, 01)$ oleh naungan, inokulasi FMA, dan interaksinya. Rasio tajuk: akar meningkat seiring dengan peningkatan tingkat naungan. Tanaman dengan inokulasi FMA memiliki rasio tajuk:akar yang lebih tinggi dibanding tanaman yang tidak diinokulasi $(\mathrm{P} \varangle 0,05)$ (Tabel 7). Rasio tajuk: akar bervariasi antara 4,74 sampai dengan 33,6. Wong et al. (2005) mengemukakan bahwa naungan meningkatkan rasio tajuk-akar pada tanaman legum yang toleran terhadap naungan yang berkisar 6,5 sampai dengan 14,2 pada 4 tingkat pencahayaan $(100 \%, 56 \%, 34 \%$, dan $18 \%$ ). Aklimatasi morfologis tanaman pakan terhadap cahaya yang rendah merupakan strategi adaptasi untuk mengkompensasi rendahnya laju fotosintesis per unit area daun.

Tabel 5. Efektivitas fungi mikoriza arbuskular (FMA) terhadap penyerapan P (\%)

\begin{tabular}{|c|c|c|c|c|}
\hline \multirow{2}{*}{ FMA } & \multicolumn{4}{|c|}{ Tingkat naungan } \\
\hline & $0 \%$ & $25 \%$ & $50 \%$ & $75 \%$ \\
\hline Indigen & $192,55 \pm 100,70^{a}$ & $117,35 \pm 22,33^{a}$ & $133,37 \pm 17,46^{\mathrm{a}}$ & $102,47 \pm 35,65^{\mathrm{a}}$ \\
\hline G. manihotis & $211,35 \pm 69,25^{\mathrm{ab}}$ & $178,51 \pm 34,80^{\mathrm{b}}$ & $141,05 \pm 14,96^{\mathrm{a}}$ & $79,87 \pm 11,72^{\mathrm{a}}$ \\
\hline Indigen $+G$. manihotis & $219,94 \pm 70,37^{\mathrm{b}}$ & $140,69 \pm 25,50^{a}$ & $137,18 \pm 9,80^{\mathrm{a}}$ & $86,80 \pm 24,47^{\mathrm{a}}$ \\
\hline
\end{tabular}

Keterangan: superskrip berbeda pada kolom yang sama menunjukkan berbeda nyata $(\mathrm{P}<0,05)$.

Tabel 6. Produksi bahan kering akar (g) pada beberapa tingkat naungan dan inokulasi fungi mikoriza arbuskular (FMA)

\begin{tabular}{lcccc}
\hline & \multicolumn{3}{c}{ Tingkat naungan } \\
\cline { 2 - 4 } FMA & $0 \%$ & $25 \%$ & $50 \%$ & $75 \%$ \\
\hline Indigen & $1,69 \pm 0,79$ & $0,88 \pm 0,36$ & $0,83 \pm 0,22$ & $0,05 \pm 0,03$ \\
G. manihotis & $0,88 \pm 0,17$ & $0,95 \pm 0,17$ & $0,87 \pm 0,22$ & $0,06 \pm 0,02$ \\
Indigen + G. manihotis & $1,60 \pm 0,08$ & $0,83 \pm 0,18$ & $0,66 \pm 0,13$ & $0,05 \pm 0,02$ \\
Tanpa inokulasi & $1,29 \pm 0,49$ & $0,84 \pm 0,06$ & $0,49 \pm 0,09$ & $0,10 \pm 0,03$ \\
Rataan & $1,36 \pm 0,52^{\mathrm{C}}$ & $0,88 \pm 0,19^{\mathrm{B}}$ & $0,71 \pm 0,22^{\mathrm{B}}$ & $0,06 \pm 0,03^{\mathrm{A}}$ \\
\hline
\end{tabular}

Keterangan: superskrip berbeda pada kolom yang sama menunjukkan berbeda sangat nyata $(\mathrm{P}<0,01)$. 
Tabel 7. Rasio tajuk-akar pada beberapa tingkat naungan dan inokulasi fungi mikoriza arbuskular (FMA)

\begin{tabular}{lcccc}
\hline \multirow{2}{*}{ FMA } & \multicolumn{4}{c}{ Tingkat naungan } \\
\cline { 2 - 5 } & \multicolumn{1}{c}{$0 \%$} & $25 \%$ & $50 \%$ & $75 \%$ \\
\hline Indigen & $5,77 \pm 2,32^{\mathrm{ab}}$ & $11,46 \pm 4,39^{\mathrm{a}}$ & $17,77 \pm 4,64^{\mathrm{a}}$ & $22,43 \pm 6,90^{\mathrm{b}}$ \\
G. manihotis & $12,77 \pm 1,76^{\mathrm{b}}$ & $12,99 \pm 3,15^{\mathrm{a}}$ & $16,52 \pm 2,86^{\mathrm{a}}$ & $33,06 \pm 4,66^{\mathrm{c}}$ \\
Indigen + G. manihotis & $6,36 \pm 0,53^{\mathrm{ab}}$ & $13,66 \pm 4,04^{\mathrm{a}}$ & $24,92 \pm 7,77^{\mathrm{b}}$ & $28,06 \pm 9,36^{\mathrm{bc}}$ \\
Tanpa inokulasi & $4,74 \pm 1,70^{\mathrm{a}}$ & $8,83 \pm 3,43^{\mathrm{a}}$ & $14,74 \pm 4,14^{\mathrm{a}}$ & $8,98 \pm 2,45^{\mathrm{a}}$ \\
\hline
\end{tabular}

Keterangan: superskrip berbeda pada kolom yang sama menunjukkan berbeda nyata $(\mathrm{P}<0,05)$.

Tabel 8. Rasio daun-batang pada beberapa tingkat naungan dan inokulasi fungi mikoriza arbuskular (FMA)

\begin{tabular}{lccccc}
\hline \multirow{2}{*}{ FMA } & \multicolumn{5}{c}{ Tingkat naungan } \\
\cline { 2 - 5 } & $0 \%$ & $25 \%$ & $50 \%$ & $75 \%$ & \multirow{2}{*}{ Rataan } \\
\hline Indigen & $1,39 \pm 0,07$ & $1,10 \pm 0,15$ & $1,00 \pm 0,01$ & $1,79 \pm 0,47$ & $1,32 \pm 0,38^{\mathrm{a}}$ \\
G. manihotis & $1,25 \pm 0,03$ & $1,03 \pm 0,05$ & $0,99 \pm 0,09$ & $1,30 \pm 0,05$ & $1,14 \pm 0,15^{\mathrm{a}}$ \\
Indigen + G. manihotis & $1,30 \pm 0,20$ & $0,99 \pm 0,18$ & $0,97 \pm 0,07$ & $1,41 \pm 0,37$ & $1,17 \pm 0,28^{\mathrm{a}}$ \\
Tanpa inokulasi & $1,54 \pm 0,14$ & $1,48 \pm 0,32$ & $1,29 \pm 0,11$ & $1,81 \pm 0,40$ & $1,53 \pm 0,30^{\mathrm{b}}$ \\
Rataan & $1,37 \pm 0,16^{\mathrm{b}}$ & $1,15 \pm 0,26^{\mathrm{a}}$ & $1,06 \pm 0,15^{\mathrm{a}}$ & $1,58 \pm 0,39^{\mathrm{c}}$ & \\
\hline
\end{tabular}

Keterangan: superskrip berbeda pada kolom atau baris yang sama menunjukkan berbeda nyata $(\mathrm{P}<0,05)$.

Puero yang diinokulasi dengan G. manihotis memiliki rasio tajuk-akar, yang paling tinggi $(\mathrm{P}<0,05)$ dibandingkan perlakuan lainnya. Demikian juga Li et al. (2009) menyimpulkan bahwa inokulasi mikoriza meningkatkan rasio tajuk-akar. Berkaitan dengan tidak adanya pengaruh FMA terhadap produksi bahan kering akar, lebih tingginya rasio tajuk-akar pada tanaman bermikoriza dibandingkan tanaman tanpa mikoriza menunjukkan bahwa tanaman bermikoriza mampu memanfaatkan hara lebih baik daripada tanaman tanpa mikoriza.

\section{Rasio Daun:Batang}

Rasio daun-batang pada $0 \%$ naungan lebih tinggi $(\mathrm{P} \varangle 0,05)$ dibandingkan rasio daun:batang pada $25 \%$ dan $50 \%$ tingkat naungan tetapi lebih rendah dibandingkan 75\% tingkat naungan (Tabel 8). Hasil ini berbeda dengan hasil penelitian Wong et al. (2005) yang menunjukkan bahwa tidak ada perbedaan rasio daun:batang tanaman legum pada tingkat pencahayaan $100 \%$, 56\%, 34\%, dan 18\%. Selain itu, tanaman dengan inokulasi FMA memiliki rasio daun:batang yang lebih rendah $(\mathrm{P}<0,05)$ dibandingkan tanpa inokulasi.

Daun memiliki nilai nutrisi yang lebih baik dibandingkan dengan batang, tetapi sebaliknya, batang memiliki fraksi dinding sel yang lebih tinggi dibandingkan daun (Apori \& Orskov, 2000; Tremblay et al., 2002; Camarao et al., 2004). Hal ini menunjukkan bahwa faktor lingkungan yang mempengaruhi rasio daun: batang pada tanaman pakan dapat berdampak pada kualitas tanaman pakan karena pengurangan proporsi daun diperhitungkan sebagai pengurangan kualitas tanaman. Rasio daun:batang puero yang berubah seiring perubahan tingkat cahaya pada $0 \%$ sampai $50 \%$ dapat menurunkan kualitas puero ditinjau dari semakin menurunnya proporsi daun tanaman tersebut.

\section{KESIMPULAN}

P. phaseoloides mampu beradaptasi hingga pada $50 \%$ naungan, tetapi naungan yang berlebih (75\%) menurunkan efektivitas inokulasi FMA terhadap produksi bahan kering dan penyerapan $\mathrm{P}$.

\section{DAFTAR PUSTAKA}

Apori, L. C. \& Ørskov. 2000. Chemical composition and nutritive value of leaves and stems of tropical weed Chromolaena odorata. Grass and Forage Science. 55:77-81.

Balai Penelitian dan Pengembangan Pertanian. 2005. Petunjuk Teknis Analisa Kimia Tanah, Tanaman, Air dan Pupuk. Departemen Pertanian RI, Jakarta.

Bolan, N. S. 2001. A critical review on the role of mycorrhizal fungi in the uptake of phosphorus by plants. Plant Soil 134:189-207.

Camarao A. P., J. B. Lourenco, S. Dutra, J-L. Hornick, \& M. Bastos Da Silva. 2004. Grazing buffalo on flooded pastures in the Brazilian Amazon region: a review. Tropical Grasslands 38:193-203

Chen X. H. \& Zhao, B. 2009. Arbuscular mycorrhizal fungi mediated uptake of nutrient elements by Chinese milk vetch (Astragalus sinicus L) grown in lanthanum spiked oil. Biol Fertil Soil 45:675-678

Cumming, J. R. \& J. Ning. 2003. Arbuscular mycorrhizal fungi enhance aluminium resistance of broomsedge (Andropogon virginicus, L.) J. Exp. Bot. 54: 1447- 1459.

Das D. K., O. P. Chaturvedi, M. P. Mandal, \& R. Kumar. 2008. Effect of tree plantations on biomass and primary produc- 
tivity of herbaceous vegetation in eastern India. Tropical Ecology 49: 95-101.

Du, J., F. H. Yu, P. Alpert, \& M. Dong. 2009. Arbuscular mycorrhizal fungi reduce effects of physiological integration in Trifolium repens. Ann. Bot. 104: 335-343.

Evitariani, L. Warly, A. Fariani, T. Ichinohe, M. Hayashida, A. Razak, \& T Fujihara. 2006. Macro mineral distribution of forages in south Sumatra during rainy and dry seasons. J. Food Agric. .Environ. 4:155-160.

Ezenwa I., O. A. Aribisala, \& M. E. Aken'ova. 1996. Dry matter yields of Panicum and Brachiaria with nitrogen fertilizations or Pueraria in an oil palm plantation. Tropical Grasslands 30:414-417.

Kanno, T., M. Saito, Y. Ando, M. C. M. Macedo, T. Nakamura \& C. H. B. Miranda. 2006. Importance of indigenous arbuscular mycorrhiza for growth and phosphorus uptake in tropical forage grasses growing on an acid, infertile soil from the Brazilian savannas. Tropical Grasslands 40: 94-101.

Korhonen J., M. M. Kytoviita, \& P. Siikamaki. 2004. Are resources allocated differently to symbiosis and reproduction in Geranium sylvaticum under different light condition. Can. J. Bot. 82: 89-95.

Kramadibrata, K. \& A. W. Gunawan. 2006. Arbuscular mycorrhizal fungi surrounding tropical kudzu and para grass. Jurnal Mikrobiologi Indonesia. 11: 97-102.

Kurniawan W., L. Abdullah \& M.A. Setiana. 2007. Produksi dan Kualitas Rumput Brachiaria humidicola (Rend.) Sch, Digitaria decumbens Stent dan Stenotaphrum secundatum (Walter) O.Kunt. di bawah Naungan Sengon, Karet dan Kelapa Sawit. Media Peternakan 30:11-17.

Latif J \& M.N Mamat. 2002. A financial study of cattle integration in oil palm plantations. Oil Palm Industry Economic Journal 2: 34-44.

Li, Y., W. Ran, R. Zhang, S. Sun, \& G. Xu. 2009. Facilitated legume nodulation, phosphate uptake and nitrogen transfer by arbuscular inoculation in an upland rice and mung bean intercropping system. Plant Soil. 315:285-296.

Lukiwati, D. R. 2007. Peningkatan produksi bahan kering dan kecernaan Pueraria phaseoloides dan Centrosema pubescens dengan batuan fosfat dan inokulasi Mikoriza arbuskular. Jurnal Ilmu-Ilmu Pertanian Indonesia 9: 1-5.

McDowell, L. R. 1997. Minerals for Grazing Ruminants in Tropical Regions. $3^{\text {rd }}$ ed. University of Florida, Gainesville, Florida, USA. pp 81-94.

Musandu, A. A. O. \& K. E. Giller. 1994. Effect of vesiculararbuscular mycorrhiza on kudzu ( Pueraria phaseoloides) growth in phosphate fixing Kenya soils. African Crop Science Journal 2:79-85
Nusantara, A.D. 2002. Tanggap semai sengon (Paraserienthes falcataria (L) Nielsen terhadap inokulasi ganda cendawan mikoriza arbuskular dan rhizobium sp. Jurnal Ilmu-Ilmu Pertanian 4:62-70.

Ricardo L., L. Ness, \& L. G. Vlek. 2000. Mechanism of calcium and phosphate release from hydroxy-apatite by mycorrhizal hyphae. Soil Sci. Soc. Am. J. 64:949-955.

Rueda, B. L., R. W. Blake, C. F. Nicholson, D. G. Fox, L. O. Tedeschi, A. N. Pell, E. C. M. Fernandez, J. F. Valentim, \& J. C. Carneiro. 2003. Production and economic potentials of cattle in pasture-based systems of the western Amazon region of Brazil. J. Anim. Sci. 81: 2923-2937.

Schroth G., E. Salazar \& J. P. Da Silva Jr. 2001. Soil nitrogen mineralization under tree crops and a legume cover crop in multi-strata agroforestry in central Amazonia: spatial and temporal patterns. Expl Agric 37: 253-267.

Shukla, A, A. Kumar, A. Jha, O. P. Chaturvedi, R. Prasad, \& A. Gupta. 2009. Effects of shade on arbuscular mycorrhizal colonization and growth of crops and tree seedlings. Agroforest Syst. 76:95-109.

Sieverding, E. 1991. Vesicular-Arbuscular Mycorrhiza Management in Tropical Agrosystems. Technical Cooperation, Federal Republic of Germany. Eschborn.

Stasiun Klimatologi Kenten. 2010. Data Iklim Tahun 2000 sampai dengan 2009. Stasiun Klimatologi Kenten, Palembang.

Tremblay, G. F., G. Belanger, K. B. McRae, \& R. Michaud. 2002. Leaf and stem dry matter digestibility and ruminal undegradable proteins of alfalfa cultivars. Can. J. Plant Sci. 82: 383-393.

Valentim, J. F. \& C. M. S. Andrade. 2005. Tropical kudzu (Pueraria phaseoloides): successful adoption in sustainable cattle production systems in the western Brazilian Amazon. Tropical Grasslands 38: 222-223.

Warly, L., A. Fariani, Evitayani, M. Hayashida, \& T. Fujihara 2006a. Mineral status of forages and grazing goats in west Sumatera, Indonesia 1. Micro mineral. J. Food Agric. Environ. 4: 204-207.

Warly, L., A. Fariani, Evitayani, M. Hayashida, \& T. Fujihara 2006b. Mineral status of forages and grazing goats in west sumatra, Indonesia 2. Macro mineral. J. Food Agric. Environ. 4: 234-236.

Wong, C. C., F Moog, \& C. P. Chen. 2005. Forage and Ruminant Livestock Integrations in Tree Crop Plantations of Southeast Asia. In: Reynold S.G. \& J. Frame (Eds). Grasslands: Developments, Opportunities, Perspectives. Science Publishers, Inc. Enfield, New Hampshire. 